\title{
Basic Life Support Awareness in Pakistan: Still in Embryonic Phase
}

\author{
Sana Abbas, Beenish Abbas, Ayesha Maqsood, Syeda Rabia, Ramesha Azam, and Hina Ishaq
}

\section{ABSTRACT}

Objectives: To gauge/evaluate the knowledge and skill of BLS trained and untrained teaching faculty members at postgraduate tertiary care training institute

\begin{abstract}
Materials and Methods: A prevalidated questionnaire comprising of 44 questions was distributed among teaching faculty of three big tertiary care, post-graduate institutes. The questions were focused on evaluating the knowledge and awareness of the participants. Total number of the participants was 345
\end{abstract}

Statistical Analysis: Data was entered and analyzed by using SPSS (version 23.0).

Results: The mean knowledge score related to basic life support was 4.57 \pm 1.81 out of total 12 points and the mean score for level of awareness regarding BLS was $34.5 \%$. Moreover, only $28.15 \%$ were aware of the current AHA guidelines

Conclusion: The low level of knowledge and awareness regarding BLS in the health care workers depicts that regular BLS hands-on- workshops should be conducted and should be a part of mandatory training.

Keywords: Basic life support, knowledge, skill.

\section{INTRODUCTION}

One of the leading cause of deaths in modern world is cardiac arrest. It is vital to ensure that health care workers at all levels of their professional development should develop adequate knowledge and skill to deliver necessary life saving measures in case of life-threatening situations. Health care providers must be competent to perform adequately in a critical situation and update their basic life support (BLS) training in timely manner. In USA BLS courses has been part of training of health care team since 1966 however, in developing countries it is not a part of mandatory training. Importance of comprehensive and up to date BLS training is even an essential requirement for laypersons according to American heart Association (AHA) chain of survival considering the fact health professionals proficiency and competency on BLS cannot be overlooked [1].

Term BLS encompasses all the techniques to sustain circulation, patient airway and breathing and to prevent
Submitted: October 14, 2021

Published: November 10, 2021

ISSN: $2593-8339$

DOI: $10.24018 /$ ejmed.2021.3.6.1106

S. Abbas*

National University of Medical Sciences, Pakistan.

(e-mail: doctor_amcollian@yahoo.com) B. Abbas

Foundation University Islamabad, Pakistan.

(e-mail: beenishabbas1982@gmail.com) A. Maqsood

Foundation University Islamabad, Pakistan.

(e-mail: amaqsood7@yahoo.com)

S. Rabia

Foundation University Islamabad, Pakistan.

(e-mail: docgeelaanee@gmail.com)

R. Azam

Foundation University Islamabad,

Pakistan.

(e-mail: ramesha.12@hotmail.com)

H. Ishaq

Foundation University Islamabad,

Pakistan.

(e-mail: bdsgraduate@gmail.com)

*Corresponding Author

cardiac arrest until advanced life support services are activated. BLS includes cardiopulmonary resuscitation (CPR) that combines the skill of applying chest compressions and mouth to mouth breathing also involves the use of automated external defibrillator (AED) [2]. Patient survival highly depends upon how prompt and efficient BLS provider response was further reinforcing the need for compulsory BLS training courses. European Resuscitation Council (ERC) provide systematic and clear guidelines on BLS training as a mandatory requirement for all [3].

However, there is unmet need to strengthen BLS training in clinical and basic sciences teachers involved in training of medical and dental undergraduate students of developing countries like Pakistan. International recommendations for CPR in adults are to ensure safety, activation of emergency services secure airway then start performing 5 to $6 \mathrm{~cm}$ deep chest compressions at the rate of 100 to 120 per minute permitting adequate chest recoil in between compressions minute [4]. After 30 chest compressions two rescue breaths 
should be given till the time AED arrives its switched on and rescuer must follow the instructions. There are recommendations to change rescuer every 2 minutes if situation permits so [5]. All members of dental team should be familiar with their responsibilities during an emergency to minimize human factors during an emergency UK resuscitation council recommends importance of team effort, situational awareness, leadership, and decision making can result in coordinated effort. In rare cases there is risk of rib or sternal fracture but benefits of CPR far outweigh the risks [6]. Latest international guidelines signify the utmost importance coordination between emergency medical dispatcher, performing of bystander CPR and timely deployment of AED which is not possible without adequate training of every team member [7]. Ideal situation would be to train as many people as possible with least resources and time one or more educational intervention like the use of virtual training devices and web-based learning can be considered to reach out to as many people as possible importance of hands-on skill can never be overlooked in BLS training programs [8].

Rationale of our study to check the knowledge and skill of BLS in teaching faculty at postgraduate tertiary care training institute many international publications are there on the topic but there is paucity of local data on the topic. Hence this survey was conducted to evaluate knowledge and perception regarding BLS and CPR among BLS trained and untrained faculty members.

\section{Methodology}

The Study will be conducted in Foundation University College of Dentistry after approval of Ethical Committee over a period of 04 months from April 2021 to July 2021.

As per American Heart association $84 \%$ is considered passing criteria for Basic Life Support workshop [10]. The minimum sample size required for this prospective crosssectional analytical study was 345 , calculated by using formula $(\mathrm{n}=[\operatorname{deff} \times \mathrm{np}(1-\mathrm{p})] /[(\mathrm{d} 2 / \mathrm{z} 21-\alpha / 2 \times(\mathrm{n}-1)+\mathrm{p} \times(1-$ p)]-open epi calculator), with $95 \%$ confidence level and $5 \%$ margin of error where the hypothesized frequency of appropriate awareness for Basic Life Support at among dental teaching faculty was considered to be $(5.6 \%+/-5)$ as reported by [9].

The questionnaire comprised a total of 44 questions across four categories that included socio-demographic characteristics, medical emergencies encountered in the tertiary care teaching hospital, knowledge of BLS as well as attitudes and perceptions relating to BLS and emergency care. The section relating to knowledge of BLS comprised 12 multiple choice questions, with a score of 6 and above being considered as a good knowledge score. Informed consent was obtained once participants had been given the opportunity to read through the study information sheet and agreed to participate in the study. Confidentiality was always maintained.

The aspects on which they were tested were about the abbreviation of BLS, AED and EMS, sequential steps in basic life support, assessment, and resuscitation techniques with regard to airway, breathing, circulation in unresponsive victims of different age groups, techniques regarding removal of foreign body obstruction, recognition of early signs of stroke and acute coronary syndrome. A specially designed Performa was used to assess the awareness on basic life support. This was followed by qualitative interview with the focus group of 20 participants which was conducted to establish a conceptual equivalence and content validity of the present questionnaire. The difficulties encountered during the pilot study were overcome during the main study. Those who participated in the pilot study were excluded from the main study.

Data was entered and analyzed by using data management software IBM SPSS (version 23.0). The descriptive statistics of continuous variables were presented as mean and standard deviation, while categorical data frequencies and percentages were used. Categorical grouped data was analyzed by Chisquare test. A p-value of $\leq 0.05$ was statistically significant.

\section{RESUlTS}

A total of 345 faculty members participated in this study. Most of the responders were females 265 (76.8\%), while 80 $(23.2 \%)$ were males. The mean age of the study group was $28.84 \pm 6.04$ years with an age-range of 21 to 51 years. There were $141(40.9 \%)$ consultants, $86(24.9 \%)$ demonstrators and $118(34.2 \%)$ house officers. Out of 345, $145(42.0 \%)$ responders were trained for Basic Life Support. Table I summarizes the demographic characteristics of the responders. About 192 (55.7\%) responders reported to have witnessed injury (e.g., cuts, broken limbs, bleeding, etc.), 217 $(62.9 \%)$ loss of consciousness, $79(22.9 \%)$ choking, 183 (53.0\%) breathing difficulty, $114(33.0 \%)$ allergic reaction and $138(40.0 \%)$ convulsions during dentistry practice as depicted in Fig. 1.

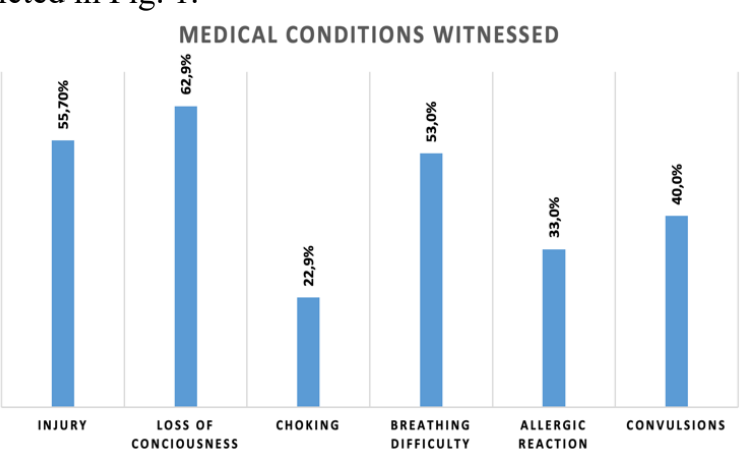

Fig. 1. Percentage of medical emergencies witnessed by responders during practice.

TABLE I: SUMMARY OF DEMOGRAPHIC CHARACTERISTICS OF RESPONDERS ( $\mathrm{N}=345)$

\begin{tabular}{ccc}
\hline \hline Characteristics & Frequency & Percentage \\
\hline \hline Age in years (mean \pm SD) & $28.84 \pm 6.04$ \\
\hline Age range & \multicolumn{2}{c}{$21-51$} \\
\hline Gender & 80 & $23.2 \%$ \\
Male & 265 & $76.8 \%$ \\
Female & & \\
Professional role & 56 & $16.3 \%$ \\
Consultant & 171 & $49.5 \%$ \\
Demonstrator & 118 & $34.2 \%$ \\
House officers & & \\
Faculty & 212 & $61.4 \%$ \\
FUCD & 54 & $15.7 \%$ \\
FUMC & 55 & $15.9 \%$ \\
FFH & 24 & $7.0 \%$ \\
AFID & 192 & $55.7 \%$ \\
\hline old) &
\end{tabular}


The mean knowledge score related to basic life support was $4.57 \pm 1.81$ out of total 12 points, where 119 (34.5\%) responders were found to have satisfactory knowledge score of $\geq 6$ points. Table II gives percentage of responders who managed to correctly answer the knowledge-based questions of basic life support. In terms of attitude towards life support training, it was reported that majority of the participants 330 (95.7\%) were interested in receiving CPR training, whereas $176(51.0 \%)$ reported to have received CPR training at least once. Irrespective of training, $144(41.7 \%)$ responders reported to provide emergency care to at least once. Attitude parameters regarding basic life support training are summarized in Table III for further details.

TABLE II: PERCENTAge AND FREQUENCY OF CORRECT ANSWERS TO THE BASIC LIFE SUPPORT KNOWLEDGE-BASED QUESTIONS

\begin{tabular}{|c|c|c|}
\hline \multirow{2}{*}{ Knowledge based Questions } & \multicolumn{2}{|c|}{ Correct answers } \\
\hline & Frequency & Percentage \\
\hline $\begin{array}{c}\text { What is the first thing to look out for during } \\
\text { a medical emergency? }\end{array}$ & $92 / 345$ & $26.7 \%$ \\
\hline $\begin{array}{l}\text { What are the steps of Basic Life Support in } \\
\text { an adult? }\end{array}$ & $169 / 345$ & $49.0 \%$ \\
\hline $\begin{array}{l}\text { What is the chest compression to breath ratio } \\
\text { for 1-rescuer child CPR? }\end{array}$ & $183 / 345$ & $53.0 \%$ \\
\hline $\begin{array}{l}\text { What is the chest compression to breath ratio } \\
\text { for 2-rescuer child CPR? }\end{array}$ & $153 / 345$ & $44.3 \%$ \\
\hline $\begin{array}{c}\text { How often should roles be switched when } \\
\text { performing 2-rescuer CPR? }\end{array}$ & $95 / 345$ & $27.5 \%$ \\
\hline $\begin{array}{c}\text { What are the correct steps to operating an } \\
\text { Automated External Defibrillator (AED) } \\
\text { device? }\end{array}$ & $219 / 345$ & $63.5 \%$ \\
\hline $\begin{array}{l}\text { Which is not a characteristic of high-quality } \\
\text { CPR? }\end{array}$ & $134 / 345$ & $38.8 \%$ \\
\hline $\begin{array}{l}\text { What is the current American Heart } \\
\text { Association Basic Life Support sequence? }\end{array}$ & $97 / 345$ & $28.1 \%$ \\
\hline What are the signs of airway obstruction? & $250 / 345$ & $72.5 \%$ \\
\hline $\begin{array}{l}\text { How would you check for responsiveness in } \\
\text { a baby? }\end{array}$ & $185 / 345$ & $53.6 \%$ \\
\hline
\end{tabular}

TABLE III: PERCEPTION AND ATTITUDE OF THE RESPONDENTS REGARDING PRACTICE/TRAINING OF BASIC LIFE

\begin{tabular}{ccc}
\hline \hline Perception and Attitude & Frequency & Percentage \\
\hline \hline $\begin{array}{c}\text { Ever received formal CPR training } \\
\text { Would like to have CPR training }\end{array}$ & 176 & $51.0 \%$ \\
Ever provided emergency care to anyone & 330 & $95.7 \%$ \\
$\quad \begin{array}{c}\text { before } \\
\text { Confident in dealing with medical emergencies } \\
\quad \begin{array}{c}\text { during practice } \\
\text { Think that CPR training should be mandatory } \\
\text { for all health professionals }\end{array}\end{array}$ & 144 & $41.7 \%$ \\
Think that CPR training as an extra work & 318 & $40.6 \%$ \\
\hline \hline
\end{tabular}

TABLE IV: COMPARISON OF BARRIERS TO PROVIDING CPR AMONG RESPONDERS TRAINED AND UNTRAINED IN CPR

\begin{tabular}{|c|c|c|c|}
\hline & $\begin{array}{c}\text { Trained in } \\
\text { CPR } \\
(n=176) \\
\end{array}$ & $\begin{array}{c}\text { Untrained in } \\
\text { CPR } \\
(n=169) \\
\end{array}$ & p-value \\
\hline \multicolumn{4}{|c|}{ Barriers in performing CPR } \\
\hline Fear, if it goes wrong & $84(47.7 \%)$ & $113(66.9 \%)$ & $<0.001$ \\
\hline Presence of blood or vomit & $64(36.4 \%)$ & $92(54.4 \%)$ & 0.001 \\
\hline Fear of injury to the victim & $85(48.3 \%)$ & $96(56.8 \%)$ & 0.114 \\
\hline $\begin{array}{l}\text { Fear of contracting disease } \\
\text { from the victim }\end{array}$ & $90(51.1 \%)$ & $74(43.8 \%)$ & 0.172 \\
\hline \multicolumn{4}{|c|}{ Willingness to perform CPR among } \\
\hline $\begin{array}{c}\text { Patient/ student/ faculty } \\
\text { member in your department }\end{array}$ & $156(88.6 \%)$ & $145(85.8 \%)$ & 0.430 \\
\hline An immediate family member & $146(83.0 \%)$ & $141(83.4 \%)$ & 0.906 \\
\hline A stranger that is an adult & $157(89.2 \%)$ & $141(83.4 \%)$ & 0.118 \\
\hline A stranger that is a child & $157(89.2 \%)$ & $135(79.9 \%)$ & 0.016 \\
\hline
\end{tabular}

A significantly greater number of responders who were trained in CPR, managed to secure a score of $\geq 6$ points in knowledge questionnaire $(63.9 \%$ vs $36.1 \%, \quad \mathrm{p}=0.01)$.
Similarly, those already trained in CPR were significantly more likely to have provided emergency care to anyone before $(71.5 \%$ vs $28.5 \%, \mathrm{p}<0.001)$ and were more confident in dealing with medical emergency situations $(72.9 \%$ vs $27.1 \%, \mathrm{p}<0.001)$. Comparison of barriers and willingness in performing CPR among trained and untrained responders is shown in Table IV. Significantly a greater number of untrained responders reported fear of something going wrong $(p<0.001)$ and presence of blood/vomit to be one of the barriers in performing CPR. Similarly, untrained responders were less likely to show willingness in performing CPR to a child.

\section{DISCUSSION}

In our study we found that although it was conducted within health professional on $42 \%$ were trained for BLS, which unfortunately was not an optimistic situation. The level of awareness regarding BLS was quite disappointing as the mean score was quite low and only $34.5 \%$ of the responders had a satisfactory knowledge score. This unsatisfactory awareness level has been observed in a few other local studies as well [10]. Similar results were also shown in a survey conducted on dental students in KSA who had an inadequate level of knowledge of BLS [11].

In another study conducted in North Kerala India, a region with a high literacy rate, it was found to have a better result than others with a mean score of $44 \%$, but still not very satisfactory [12]. In a study conducted in a developed country like France surprisingly not very encouraging results were reported. More than $75 \%$ of the medical students in their final years, did not have adequate knowledge about BLS [13]. All these observations do not point towards a very promising scenario as we expect the health professional, whether medical, dental, or paramedics to have an adequate know how and expertise to perform CPR [14]. In our study it was found that those trained in CPR had a good basic knowledge, this was also documented in another study done in Rawalpindi, Pakistan [15]. Thus, emphasizing the point that these CPR courses have a positive impact on the knowledge of the responders and make them better care providers in case of emergency. BLS training needs to be continuously revised and re assessed which will help in achieving a cognitive level necessary for sufficient, high quality BLS [16]. Studies have shown that refresher courses should be conducted with 6 months gap, not only to stay updated with the latest guidelines but also to help retain the knowledge [17]. As CPR is a psychomotor skill the correct implementation of all steps cannot be overlooked, and that is only possible with regular practice of the steps according to the recommended guidelines [18]. The emergency management protocols are undergoing continuous revision and the new AHA guidelines are being emphasized in new ongoing CPR training programme but a very few only $28.15 \%$ were aware of the current AHA guidelines in our study. This was seen in another study done in Saudi where $27.6 \%$ were aware of the recent guidelines. similar results were reflected in a study done by Saquib et al. where only $10 \%$ of responders knew about the new sequence [19].

The use of AED along with high quality CPR may double the survival rate in patients with cardiac arrest hence 
emphasizing the need of adequate ability in operating an AED [20]. Many of the participants in our study $(63.5 \%)$ had an ample knowledge of operating an AED, but if we compare it to another study done in USA an extremely high percentage of participants (85\%) had an adequate knowledge and skill regarding the use of AED [21]. An encouraging statistic in our study was that majority of the participants $(95.7 \%)$ were interested in receiving CPR training and most of them (92.2\%) thought that CPR should be mandatory. Such promising attitude towards making this training mandatory was seen in other studies as well [12]. Though contradictory results were observed in another research where lack of interest was seen in BLS training, the reasons being quite coercive like tough training schedules, inadequate resources, limited number of BLS programs and unfortunately the lack of interest in learning of resuscitation procedures [10]. Nevertheless, the importance of BLS cannot be overemphasized, as good knowledge and skill will help achieving better survival rates [22].

\section{LIMITATIONS AND RECOMMENDATIONS}

This was a questionnaire-based study which tests the knowledge of the participant that cannot be exactly verified and moreover the psychomotor skill of the responder cannot be assessed. As already discussed, the time lapse since the BLS training also affects the knowledge and skill. Future studies are required which can assess basically the skill of the responders in a particular setting, and which could be further validated by a pre-training and post-training test for assessment of knowledge and skill. Furthermore, these tests can be repeated after a period of four or six months to measure the retention of knowledge and skill. The aim of this study and any future studies is to apply the knowledge of BLS into development of prompt and effective skills which will help in refining lifesaving services being provided in Pakistan.

\section{ACKNOWLEDGMENT}

None.

\section{FUNDING}

None.

\section{CONFLICT OF INTEREST}

Authors declare that they do not have any conflict of interest.

\section{REFERENCES}

[1] Ojifinni K, Motara F, Laher AE. Knowledge, attitudes and perceptions regarding basic life support among teachers in training. Cureus. 2019; 11(12): 4-13.

[2] Schiefer JL, Schuller H, Fuchs PC, Bagheri M, Grigutsch D, Klein M, et al. Basic life support knowledge in Germany and the influences of demographic factors. PLoS One. 2020; 15(8): e0237751.

[3] Kwiecień-Jaguś K, Mędrzycka-Dąbrowska W, Galdikienė N, Via Clavero G, Kopeć M. A cross-international study to evaluate knowledge and attitudes related to basic life support among undergraduate nursing students - a questionnaire study. Int J Environ Res Public Health. 2020; 17(11): 1-11.

[4] Bench S, Winter C, Francis G. Use of a virtual reality device for basic life support training: prototype testing and an exploration of users' views and experience. Simul Healthc. 2019; 14(5): 287-92.

[5] McKernon SL, Kaura L, Taylor KH, Reid S, Balmer MC. An update on current resuscitation council (UK) guidelines. Dent Update. 2017; 44(4): 341-50.

[6] Del Mar Requena-Mullor M, Alarcón-Rodríguez R, Ventura-Miranda MI, García-González J. Effects of a clinical simulation course about basic life support on undergraduate nursing students' learning. Int $J$ Environ Res Public Health. 2021; 18(4): 1-9.

[7] Vineeth Chandran K, Abraham S V. Basic life support: Need of the hour - a study on the knowledge of basic life support among young doctors in india. Indian J Crit Care Med. 2020; 24(5): 332-5.

[8] González-Salvado V, Rodríguez-Ruiz E, Abelairas-Gómez C, RuanoRaviña A, Peña-Gil C, González-Juanatey JR, et al. Training adult laypeople in basic life support. A systematic review. Rev Española Cardiol. 2020; 73(1): 53-68.

[9] Sudeep CB, Sequeira PS, Jain J, Jain V, Maliyil M. Awareness of basic life support among students and teaching faculty in a dental college in coorg. Karnataka. 2013; 2(1): 4-9.

[10] Irfan B, Zahid I, Khan MS, Khan OAA, Zaidi S, Awan S, et al. Current state of knowledge of basic life support in health professionals of the largest city in Pakistan: A cross-sectional study. BMC Health Serv Res. 2019; 19(1): 1-7.

[11] Al-Mohaissen MA. Knowledge and attitudes towards basic life support among health students at a Saudi women's university. Sultan Qaboos Univ Med J. 2017; 17(1): e59-65.

[12] Nambiar M, Nedungalaparambil NM, Aslesh OP. Is current training in basic and advanced cardiac life support (BLS \& ACLS ) effective? A study of BLS \& ACLS knowledge amongst healthcare professionals of. World Journal of Energency Medicine. 2016; 7(4): 263-9.

[13] Kurz MC, Schmicker RH, Leroux B, Nichol G, Aufderheide TP, Cheskes S, et al. Advanced vs. Basic Life Support in the Treatment of Out-of-Hospital Cardiopulmonary Arrest in the Resuscitation Outcomes Consortium. Resuscitation. 2018; 128: 132-7.

[14] Niemi-Murola L, Mäkinen M, Castren M, ECCE Study Group. Medical and nursing students' attitudes toward cardiopulmonary resuscitation and current practice guidelines. Resuscitation. 2007; 72(2): 257-263.

[15] Zamir Q, Nadeem A, Rizvi AH. Awareness of cardiopulmonary resuscitation in medical-students and doctors in Rawalpindi-Islamabad, Pakistan. JPMA. The Journal of the Pakistan Medical Association. 2012; 62(12): 1361-1364.

[16] Carvalho APL, Nardello LCL, Fernandes FS, Bruno FP, Paz LR, Iglecias EF, et al. Effects of contemporary irrigant activation schemes and subsequent placement of an interim dressing on bacterial presence and activity in root canals associated with asymptomatic apical periodontitis. J Clin Med. 2020; 9(3): 854.

[17] Passali C, Pantazopoulos I, Dontas I, Patsaki A, Barouxis D, Troupis $\mathrm{G}$, et al. Evaluation of nurses' and doctors' knowledge of basic \& advanced life support resuscitation guidelines. Nurse Educ Pract. 2011; 11(6): 365-369.

[18] Kardong-Edgren S, Adamson KA. BSN medical-surgical student ability to perform cpr in a simulation: recommendations and implications. Clin Simul Nurs. 2009; 5(2).

[19] Saquib SA, Al-Harthi HM, Khoshhal AA, Shaher AA, Al-Shammari $\mathrm{AB}$, Khan A, et al. Knowledge and attitude about basic life support and emergency medical services amongst healthcare interns in university hospitals: a cross-sectional study. Emerg Med Int. 2019; 2019: 1-8.

[20] Bylow H, Karlsson T, Claesson A, Lepp M, Lindqvist J, Herlitz J. Selflearning training versus instructor-led training for basic life support: A cluster randomised trial. Resuscitation. 2019;139: 122-32.

[21] Watanabe K, Lopez-Colon D, Shuster JJ, Philip J. Efficacy and retention of Basic Life Support education including Automated External Defibrillator usage during a physical education period. Prev Med Reports. 2017; 5: 263-7.

[22] Steen PA, Kramer-Johansen J. Improving cardiopulmonary resuscitation quality to ensure survival. Curr Opin Crit Care. 2008; 14(3): 299-304. 